Pak. j. sci. ind. res. Ser. A: phys. sci. 2021 64A(3) 265-274

\title{
A Comparative Study of Support Vector Machine and Maximum Likelihood Classification to Extract Land Cover of Lahore District, Punjab, Pakistan
}

\author{
Fatima Mushtaq ${ }^{\text {a }}$, Khalid Mahmood ${ }^{\text {bd*, Mohammad Hamid Chaudhry }}{ }^{\text {a }}$, Rahat Tufail ${ }^{c}$ \\ ${ }^{a}$ Center for Geographical Information System, University of the Punjab, Lahore-54590, Pakistan \\ ${ }^{b}$ Department of Space Science, University of the Punjab, Lahore-54590, Pakistan \\ ${ }^{\mathrm{c}}$ College of Earth and Environmental Science, University of the Punjab, Lahore-54590, Pakistan \\ ${ }^{\mathrm{d}}$ Remote Sensing, GIS and Climatic Research Laboratory, University of the Punjab, Lahore-54590, Pakistan
}

(received December 2, 2019; revised June 9, 2020; accepted July 13, 2020)

\begin{abstract}
The advent of technological era, the scientists and researchers develop machine learning classification techniques to classify land cover accurately. Researches prove that these classification techniques perform better than previous traditional techniques. In this research main objective is to identify suitable land cover classification method to extract land cover information of Lahore district. Two supervised classification techniques i.e., Maximum Likelihood Classifier (MLC) (based on neighbourhood function) and Support Vector Machine (SVM) (based on optimal hyper-plane function) are compared by using Sentinel-2 data. For this optimization, four land cover classes have been selected. Field based training samples have been collected and prepared through a survey of the study area at four spatial levels. Accuracy for each of the classifier has been assessed using error matrix and kappa statistics. Results show that SVM performs better than MLC. Overall accuracies of SVM and MLC are $95.20 \%$ and $88.80 \%$ whereas their kappa co-efficient are 0.93 and 0.84 respectively.
\end{abstract}

Keywords: maximum likelihood classification, support vector machine, land cover, accuracy assessment, kappa statistics

\section{Introduction}

Land cover and land use. Land is a basic necessity for living beings and its utility varies from purpose to purpose. Generally, it is described as a space on the surface of the earth at which living beings perform their activities. It is multi-resource base for mankind as it provides shelter, forestry, fruits, vegetables, water, and clothes. Nation's economy and growth mainly depends upon the land of that region (Chiemelu and Onwumere, 2013). Usually land cover and land use is misunderstood and think of alternate of each other but in reality it's the opposite. Land cover represents the physical material at the earth's surface like urban buildings, forests, meadows, snow, lakes, mountains, whereas land use is described as how this physical material is used by human beings like residential, commercial, and recreational (Brar, 2013). Lahore is the metropolitan city in Punjab Province of Pakistan and recent infrastructure change in the land cover expands the urban area (Riaz et al., 2014).

*Author for correspondence; E-mail: khalid.spsc@pu.edu.pk khalid.m270@yahoo.com
Role of remote sensing and GIS in land cover. Land cover directly impacts the diversity of living beings, water cycle of region and quality of environment. Important information of the land cover is now easily monitor and directly record with the help of remote sensing instruments (Abdi, 2020; Ngo et al., 2020; Cui, 2019). Advancement in remote sensing (RS) and geographical information system (GIS) techniques provides remarkable applications which helps in understanding the complex dynamics of environment. In this regard spatial analysis like mapping of land cover, land cover change detection and land cover classification are playing vital role in providing important land cover information not only at local but also at global level (Gupta and Srivastava, 2010). With the help of appropriate correlation tools of remote sensing and GIS, land cover information can be handled accurately and can be mapped timely with limited labour. In remote sensing satellite data application, accuracy of land cover classification is highly preferable (Wulder et al., 2018; Hutt et al., 2016).

Parametric and non-parametric classifiers. Parametric and non-parametric classifiers are the most generalized 
terms in classification techniques. Parametric classifiers consider that the data distribution for each individual class is normal. The most popular, conventional and widely used parametric classifier is Maximum Likelihood Classification (MLC). Based upon the mean and covariance of the data this classifier generates decision surfaces (Srivastava et al., 2012). Non-parametric classifier is not based upon the normal distribution of the data and assumption about statistical nature of the data is negligible. One of the non-parametric classifiers is the support vector machine which consists of various machine learning algorithms and is used for classification purpose (Varma et al., 2016). In 1971, SVM theory is proposed as a binary classification method by Vapnik and Chervonenkis and details of SVM was discussed by Vapnik in 2000. SVM being an artificial intelligence machine learning algorithm have been used in diverse applications of remote sensing (Varma et al., 2016; Taati et al., 2015; Ustuner et al., 2015).

Current problems and challenges. Satellite remote sensing is the most advance technology of this era and provides timely and accurate geospatial information of land cover of any region all around the world (Puletti et al., 2018; Olmanson and Bauer, 2017). Researchers and scientists reviewed numerous image classification techniques to extract and map land cover information (Thanh and Kappas, 2018). Today, various satellites have been launched and data availability is not the issue anymore but the real problem lies when it comes to its processing. Classification of these satellite data and extraction of important information without compromising its accuracy is the real challenge. Conventional classification methods have their limitations in processing high dimension image data in large amount, as this data also contains diverse spectral characteristics and spatial distribution of objects on the surface of the earth. Also, it is difficult and sometimes not possible to obtain complete sample sets and priori knowledge. So, common methods fail to overcome these challenges as they lack the ability of self-learning process (Abdi, 2020; Ngo et al., 2020; Cui, 2019).

To overcome these limitations machine learning techniques are playing vital role as they self-learn through the mechanism. Many researches have been conducted to find the best technique for land cover classification but to know the most suitable technique more comparative studies are required. Nitze et al. (2012) has compared three such machine learning classifiers with the conventional technique to classify different crop types. With the help of rapideye (5m resolution) data SVM significantly gave better performance. The overall accuracy obtained by SVM method was $68.6 \%$. Similarly, Thanh and Kappas, 2018 , compared and examined the performances of three classifiers using sentinel-2 (10 m resolution) satellite data which are random, k-nearest neighbour, and support vector machine. Classification results show high overall accuracy in between 90-95\%. But SVM showed the highest overall accuracy in comparison with the other classifiers.

The study in hand has tended to compare and evaluate two of the supervised classifiers, one is Support Vector Machine (SVM) and the other is Maximum Likelihood Classification (MLCC). The suitable method is identified using remote sensing satellite data of Sentinel-2 by comparing the classification accuracy in the Lahore district, Punjab Pakistan.

\section{Materials and Methods}

Study area. Lahore is the capital of Punjab province and a rapidly growing metropolitan has been chosen as the study area in this research. Associations of the study area are shown in Fig. 1. Lahore is one of the developed districts in Punjab Pakistan. In terms of population and urban sprawl, Lahore is the second largest city in Pakistan after Karachi. It stretches over an area of 1772 $\mathrm{km}^{2}$ (Riaz et al., 2014) and population is about 11.13 million (Census, 2017). It is located in the north-eastern part of the Punjab province and lies on the left bank of Ravi river. Its geographical extension lies within latitude from $31^{\circ} 15^{\prime} \mathrm{N}$ to $31^{\circ} 44^{\prime} 2^{\prime \prime} \mathrm{N}$ and longitude from $74^{\circ} 1^{\prime} 11^{\prime E}$ to $74^{\circ} 38^{\prime} 10^{\prime \prime} \mathrm{E}$. Because of the river, its land is composed of fertile alluvial plain with a slope towards south east. Its underground water table is about $35-40 \mathrm{~km}$ deep (non-drinkable) and range of height above the sea level is between 680 to 700 feet with 1 feet slope gradient after every 5 to $10 \mathrm{~km}$. The water used for drinking purpose is available at the depth of $125-150 \mathrm{~m}$ (Riaz et $a l ., 2014)$. It is located in subtropical climatic zone and its temperature and rainfall varies. The only precipitation source of this area is monsoon season (Sajjad et al., 2015). Soil and climate of this region is suitable for every type of crops (Riaz et al., 2014).

Data sets. The Sentinel-2A datasets used in this study are acquired from Copernicus open access hub which is operated by European space agency (ESA) on $29^{\text {th }}$ March 2018, with no cloud covering the area. Study area does not lie in one grid that's why two images 


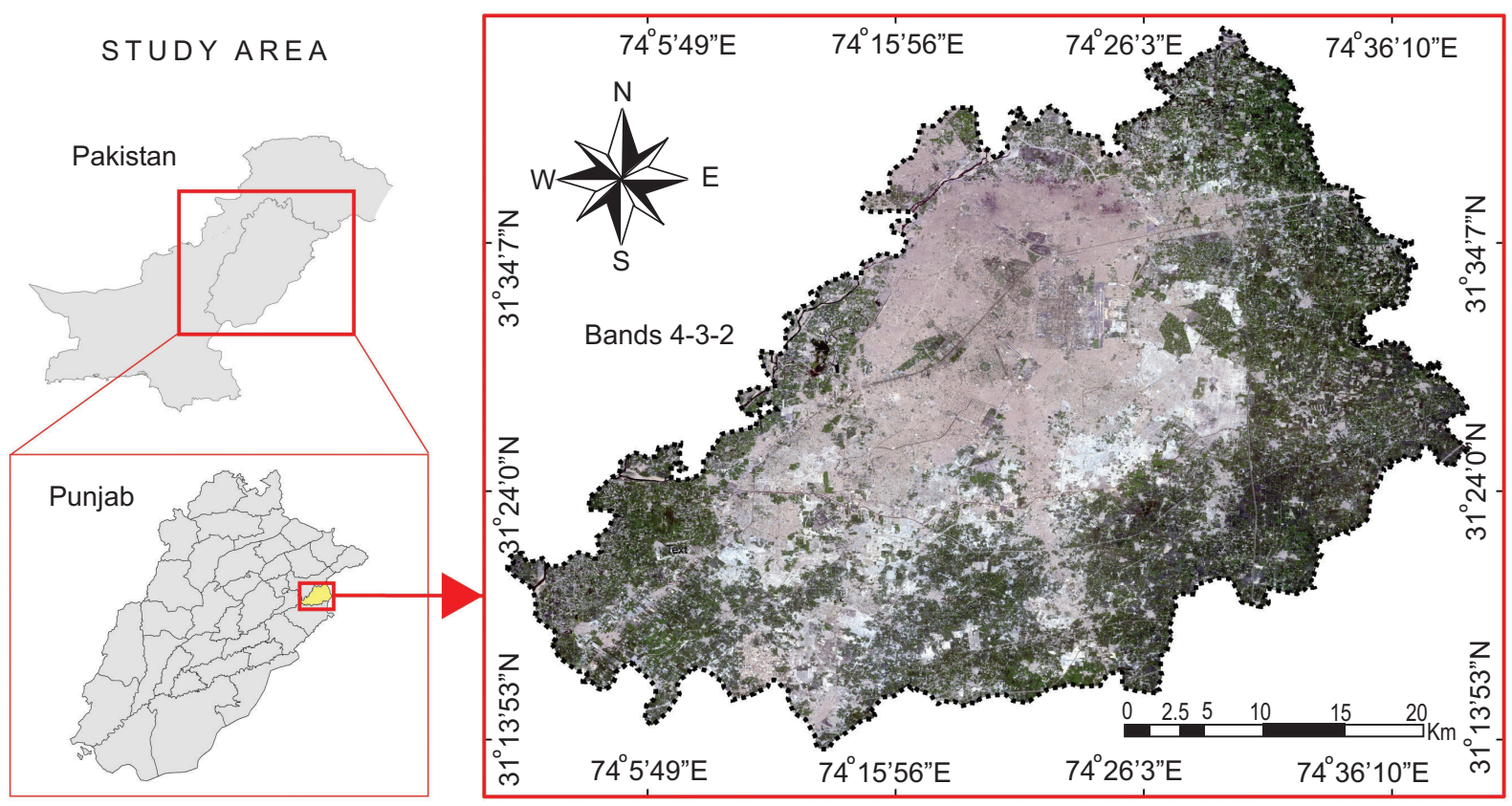

Fig. 1. Map of study area.

were used from MSI sensor with reference numbers of T43SDR and T43RDQ under the reference grid system of Sentinel-2. To minimize the seasonal effect, both images were selected with similar calendar date. The total 10 bands (optical, near infrared and short wave infrared bands) of sentinel-2A dataset were selected for image classification. Spectral and spatial ranges of these 10 bands can be seen in Table 1. In order to minimise the computational time a subset of images according to vector district boundary was considered in the study. Four different sets of representative training polygons were created using stratified random sampling technique. Map of 400 training samples can be seen in Fig. 2. In addition, 250 reference points were also collected

Table 1. Spectral and spatial information of sentinel-2

\begin{tabular}{llll}
\hline \hline $\begin{array}{l}\text { Spectral } \\
\text { bands }\end{array}$ & $\begin{array}{l}\text { Wavelength } \\
\text { description }\end{array}$ & $\begin{array}{l}\text { Wavelengths } \\
(\mathrm{im})\end{array}$ & $\begin{array}{l}\text { Resolution } \\
(\mathrm{m})\end{array}$ \\
\hline 2 & Blue & 0.490 & 10 \\
3 & Green & 0.560 & 10 \\
4 & Red & 0.665 & 10 \\
5 & Vegetation red edge & 0.705 & 20 \\
6 & Vegetation red edge & 0.740 & 20 \\
7 & Vegetation red edge & 0.783 & 20 \\
8 & NIR & 0.842 & 10 \\
9 & Narrow NIR & 0.865 & 20 \\
12 & SWIR & 1.610 & 20 \\
13 & SWIR & 2.190 & 20 \\
\hline \hline
\end{tabular}

through surveying the study area for accuracy assessment or validation (Fig. 3).

Satellite image interpretation. Atmospheric corrections are not always required for image classification when the acquisition date of satellite image is same specifically when desired classes are computed from spectral signature but it is very important when one wants to do change detection (Chrysoulakis et.al., 2010). According to Vanonckelen et al. (2013), atmospheric corrections are necessary when more than one image is used at different temporal level. The Sentinel-2A imagery had already been corrected atmospherically and geometrically,

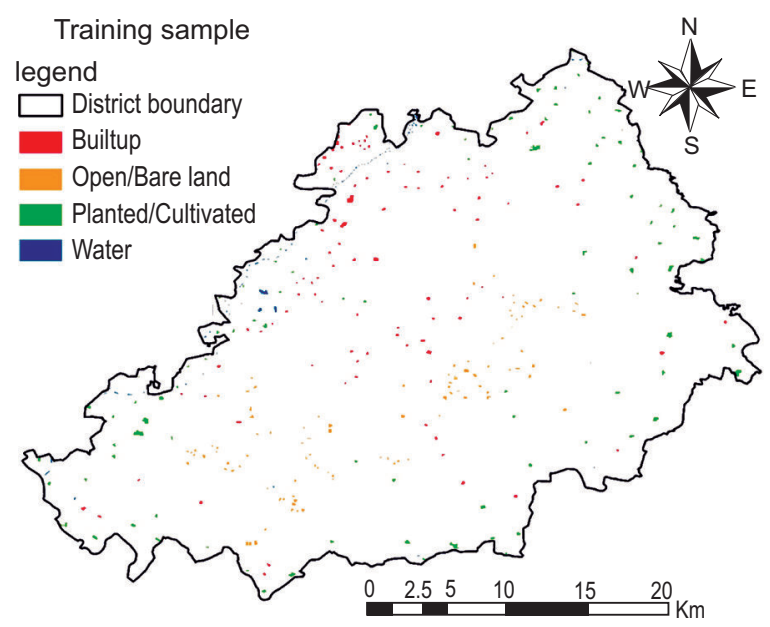

Fig. 2. Spatial distribution of training samples. 


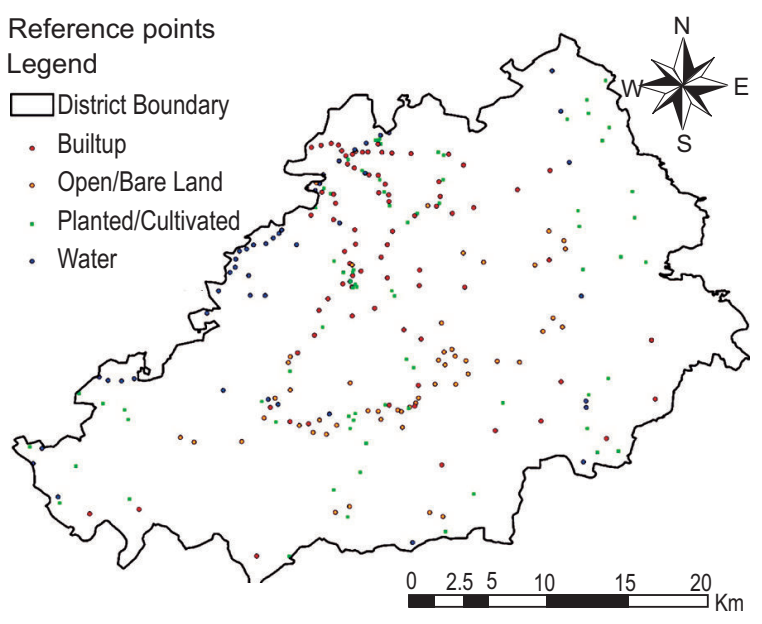

Fig. 3. Spatial distribution of reference/validation data.

and ortho-rectified. The Sentienl-2A imagery was imported into Erdas Imagine 2014 software and georeferencing of the image was initially checked with a vector data layer of the area. The layers were stacked together and the output image file was ready to be used. The swath width of these satellite images was $290 \mathrm{~km}$ by $290 \mathrm{~km}$ so the images were subset to study area in order to get a small portion of the image from large data file. In this way unnecessary imagery data cut off from the image and better analysis could be performed at the study area.

Sub-setting of the data also speeds up the processing time of the image especially in the case of SVM image

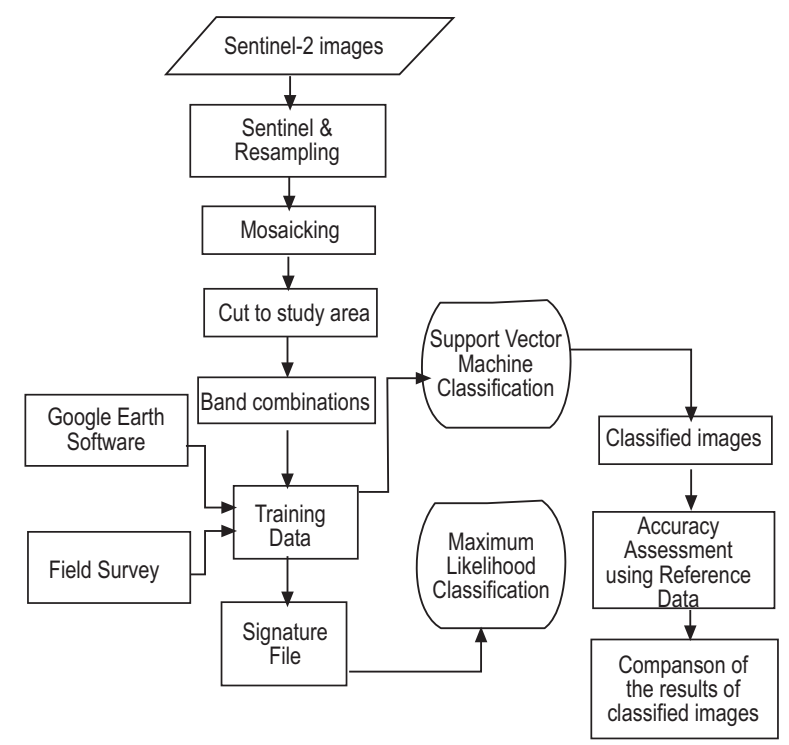

Fig. 4. Flow chart of methodology. classification. Same number of bands is used and orderly stacked (Band 2, 3, 4, 5, 6, 7, 8, 9, 11, 12) to minimize the biasness which is usually caused by using different band combination. In this research sampling of the training area and reference data is generated using polygon and point vector design respectively, for each land cover type. Erdas Imagine and R software is used for classification in this research. For the selection of land cover types, expert opinion, Google Earth imagery and different band combinations were applied. Four land cover classes were determined from Sentinel-2A satellite imagery in the year of 2018.

Maximum likelihood classification (MLC). The MLC method examines statistical data like covariance and variances of the selected class signatures when assigning values to the unknown pixels from represented class signature file. This method is based upon Bayes' theorem of decision making in which the distribution of the data in multidimensional space is linear or normal. With this assumption of linear distribution, covariance matrix and mean vector specifies a class. These two parameters are given to each pixel value. In order to compute the cell relevance to the class, statistical probability is calculated for each class. With prior specification of weightage each pixel has been identified to be a member of landcover class to which it has highest similarity under the rules (Srivastava et al., 2012). Likelihood of unknown value from known class value is calculated by the following Bayesian equation (1) (Otukei and Blaschke, (2010).

$\mathrm{D}=\ln \left(\mathrm{a}_{\mathrm{c}}\right)-\left[0.5 \ln \left(\left|\operatorname{cov}_{\mathrm{c}}\right|\right)\right]-\left[0.5\left(\mathrm{X}-\mathrm{M}_{\mathrm{c}}\right) \mathrm{T}\left(\operatorname{cov}_{\mathrm{c}}-\right.\right.$ 1) $\left.\left(\mathrm{X}-\mathrm{M}_{\mathrm{c}}\right)\right]$

where;

$\mathrm{D}=$ likelihood/ weighted distance; $\mathrm{ac}=$ probability percentage that any candidate pixel is a member of class $\mathrm{c}$ (is entered from a priori knowledge or default to 1.0); $\mathrm{c}=$ specific class; $\mathrm{X}=$ measurement candidate pixel; $\operatorname{cov}_{\mathrm{c}}=$ covariance matrix of the pixels in the sample of class $\mathrm{c} ; \mathrm{Mc}=$ mean vector of the sample class $\mathrm{c} ;\left|\operatorname{cov}_{\mathrm{c}}\right|$ $=$ determinant of covariance matrix; $\operatorname{cov}_{\mathrm{c}}-1=$ inverse of covariance matrix; $\ln =$ natural logarithm function; $\mathrm{T}=$ transposition function

Support vector machine (SVM) classification. SVM uses kernel functions defined by users in order to map the non-separable decision boundaries from an original dataset into separable decision boundaries of feature 
space or higher multi-dimensional space. SVMs are non-parametric supervised learning algorithms based on statistics. The algorithm finds an Optimal Separating Hyper-plane (OSH) between each pair of classes. This OSH is obtained by using training data from the study area. Therefore, the main purpose of SVM is to find out the OSH among all other separating hyper-planes which is achieved through an optimization problem by using quadratic programming methods and Lagrange multipliers (Szuster et al., 2011). All hyper-planes separate two classes but OSH minimizes the generalization error in classification by maximizing the margins (distance) between the two classes. The support vectors are that data points which lie at the edge of each class hyperplane in higher multi-dimensional space and are very close to the OSH (Szuster et al., 2011). Suppose training dataset with $\mathrm{n}$ number of samples, represented as:

$\{x i, y i\}, i=1,2, \ldots, n$

where;

$\mathrm{xi}=\mathrm{Lm}(\mathrm{m}$-dimensional vector $) ; \mathrm{yi}=\{-1,+1\},(1$ represents each class label)

If a vector $\mathrm{W}$ and scalar $\mathrm{b}$ can satisfy the following two inequality equations (equation (2) and equation (3)) then training dataset can be linearly separated. Equation (4) represents the constraint that must be satisfied in order to achieve a completely and linearly separable hyper-plane between two classes.

W. $x i-b=1$ for all $y=+1$

W. $x i-b=1$ for all $y=-1$

yi $(W \cdot x i-b)=1$

Compared to traditional approaches researches shows that SVM algorithms produce results of higher accuracies and depends on following three parameters i.e. the kernel, its parameters and algorithm of SVM.

Scheme of classification. Keeping in view the scope and the spatial $(10 \mathrm{~m})$ resolution of the image following scheme was developed Fig. 4. and Table 2.

- Built-up area: land use area consists of construction material i.e., commercial, industrial, road network and residential

- Planted/cultivated area: this area includes land under various crops, parks and green belts
Table 2. Land cover classification scheme and training points

\begin{tabular}{llll}
\hline \hline Classes & $\begin{array}{l}\text { Actual land cover type } \\
\text { (satellite image) }\end{array}$ & $\begin{array}{l}\text { Training } \\
\text { polygons }\end{array}$ & $\begin{array}{l}\text { Validation } \\
\text { pixels }\end{array}$ \\
\hline Built up & Residential, commercial, & 25 & 78 \\
area & industrial, road network & 50 & \\
& and educational area & 75 & \\
Planted/ & Parks, cultivated and & 100 & 75 \\
cultivated & non-cultivated lands & 50 & \\
area & & 75 & \\
& & 100 & \\
Water & Open water land & 25 & \\
bodies & & 50 & \\
& & 75 & \\
& & 100 & \\
Open/ & Barren land, sand, & 25 & \\
bare area & recreational and & 50 & \\
& undeveloped land & 75 & \\
& & 100 & \\
\hline \hline
\end{tabular}

- Water bodies: contains river, lakes, ponds and lakes

- Open/bare area: consists of undeveloped land and open spaces

To overcome the noise problem, polygon based approach is used. MLC is performed in Erdas imagine 2014 software while SVM is performed in R software.

Accuracy assessment. Accuracy assessment of the classifiers is evaluated with the help of reference datasets. Error matrix or confusion matrix measures the accuracy of the classification result by comparing it with validation data. Kappa co-efficient is a well-known parameter in accuracy assessment and was computed by the following equation 5:

$\mathrm{K}=\frac{\mathrm{N} \sum_{\mathrm{i}=1}^{\mathrm{r}} \mathrm{X}_{\mathrm{ii}}-\sum_{\mathrm{i}=1}^{\mathrm{r}}(\mathrm{Xi+})(\mathrm{x}+\mathrm{i})}{\mathrm{N}^{2}-\Sigma_{\mathrm{i}=1}^{\mathrm{r}_{1}}\left(\mathrm{x}_{\mathrm{i}+}\right)\left(\mathrm{x}_{+\mathrm{i}}\right)}$

where;

$\mathrm{N}=$ number of observations; $\mathrm{r}=$ number of rows in matrix; $X_{\mathrm{ii}}=$ number of observation in ith row and column; $X_{+\mathrm{i}}=$ marginal total of $\mathrm{r}$ row; $\mathrm{X}_{\mathrm{i}+}=$ marginal total of ith column.

Overall accuracy measures ratio of the correctly classified pixels to number of reference pixels, whereas producer's accuracy is the count of accurate pixels, among total pixels of same category. While the user's accuracy measures overall accuracy, not class specific. The 


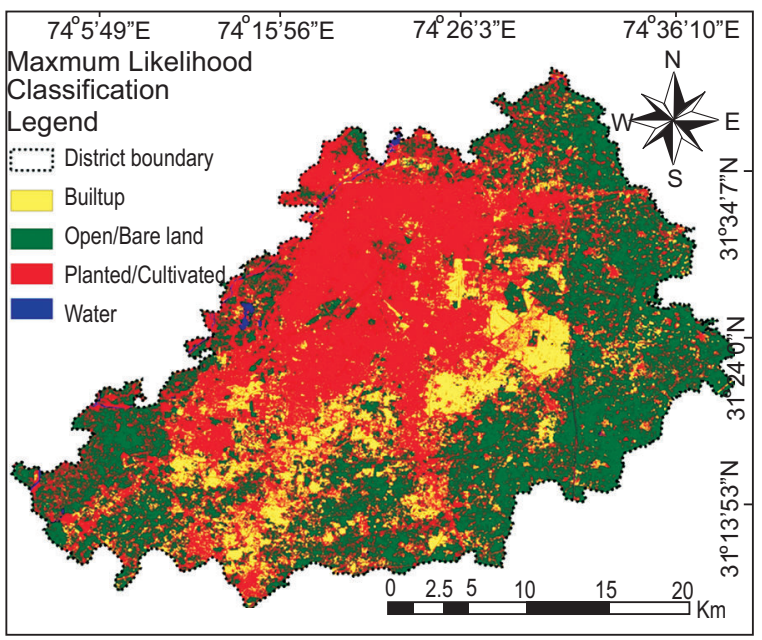

Fig. 5. Land cover map produced using MLC of Sentinel-2 for year 2018

producer's accuracy and user's category measurements are actually related to error of omission and error of commission respectively (Gupta and Sirivasstava, 2010).

\section{Results and Discussion}

MLC results. Land cover classification maps for 10$m$ resolution Sentinel-2 image were produced using MLC method. Four different training sample size were used i.e. 100, 200, 300 and 400 in order to know the effect of training dataset size. These datasets show different percentages of overall accuracy (Fig. 5).

An increase in the number of training samples size decreases the overall accuracy in MLC. It is due to the fact that in MLC decision boundaries are produced with the help of likelihood pixels not from learning algorithm and an increase in the number of training pixels' size,

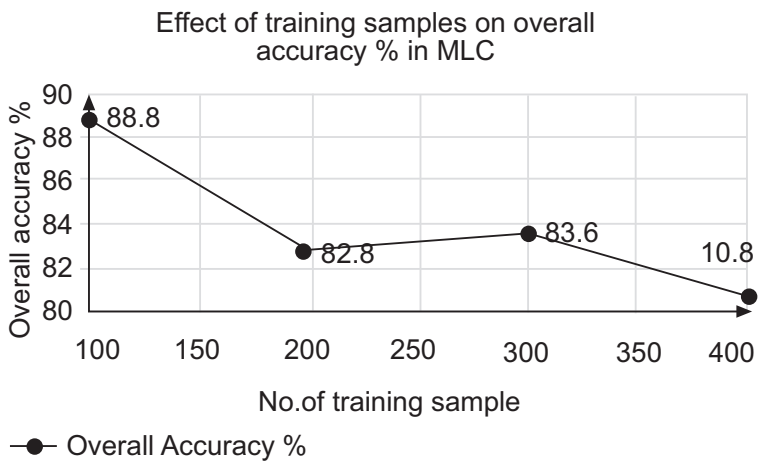

Fig. 6. Effect of training samples on overall accuracy in MLC. mean and median parameter of the dataset changes and mixed pixel problem generates. Accuracy of MLC is highly dependent on training samples. Abrupt trend can be seen in Fig. 6, as accuracy is not directly and inversely proportional to the size of training sample but general trend shows inverse relation. The highest overall accuracy of MLC (88.80 \%) was computed using 100 training polygon sizes while lowest overall accuracy was $80.80 \%$ using 400 dataset size (Fig. 6). Overall accuracy and kappa statistics of MLC with various dataset sizes can be seen in Table 3 .

SVM results. SVM classification also performed on same datasets i.e. Sentinel-2 and four different training data size. Overall accuracy of SVM increases as the number of training dataset increase but the effect of sample size is minor (Fig. 7).

SVM is a machine learning technique and when training sample size increases, algorithm has more data to find support vectors that achieve larger margin and as a result

Table 3. Overall Accuracy and Kappa statistics of MLC and SVM in tabular form

\begin{tabular}{llllll}
\hline \hline & MLC & & & \multicolumn{2}{l}{ SVM } \\
\cline { 2 - 3 } $\begin{array}{l}\text { No of } \\
\text { training } \\
\text { datasets }\end{array}$ & $\begin{array}{l}\text { Overall } \\
\text { accuracy } \\
\%\end{array}$ & $\begin{array}{l}\text { Kappa } \\
\text { statistics }\end{array}$ & & $\begin{array}{l}\text { Overall } \\
\text { accuracy } \\
\%\end{array}$ & $\begin{array}{l}\text { Kappa } \\
\text { statistics }\end{array}$ \\
\hline 100 & 88.80 & 0.8462 & & 94.00 & 0.9188 \\
200 & 82.80 & 0.7662 & & 94.40 & 0.9241 \\
300 & 83.60 & 0.7782 & & 94.80 & 0.9294 \\
400 & 80.80 & 0.7375 & 95.20 & 0.9348 \\
\hline \hline
\end{tabular}

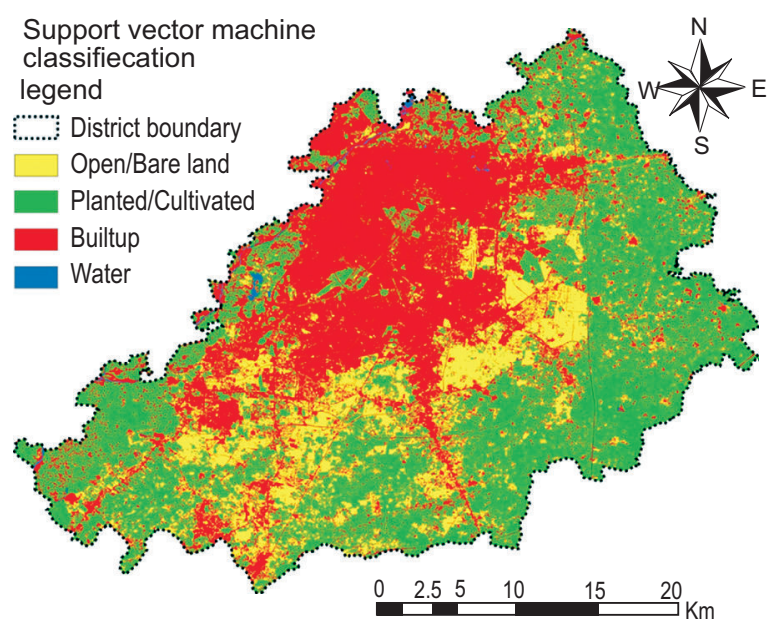

Fig. 7. Land cover map produced using SVM of Sentinel-2 for year 2018. 
generalization error become minimum. The highest overall accuracy using SVM algorithm is $95.00 \%$ and the number of training dataset (400) is also maximum (Fig. 8). Table 3 shows the kappa statistics and overall accuracy of SVM using different sizes of training datasets.

Comparison of MLC and SVM. Highest overall accuracy results from both of the classification techniques were selected for the comparison. Number of training samples for each classification method is different i.e. 100 for MLC and 400 for SVM. Error matrices for each classification method were produced in order to analyse land cover class separation performance for each method with overall accuracies. Difference is obvious between two methods:

The accuracy of land cover classification in SVM method is not dependent upon size of the training samples and results are almost same with smaller or larger number of training sample. In contrast to it, accuracy of land cover classification in MLC method is highly dependent upon the size of the training sample (Fig. 9). While selecting the size, a researcher has to be very careful.

Also SVM method shows more spatially cohesive map than that of MLC. Built-up areas are also more delineated with SVM method, and accuracy values reflect these differences. The MLC method produced the lower overall accuracy of $88.80 \%$ as expected. MLC separates the planted/cultivated land and open/bare land effectively while it is less effective in case of water and built-up. Out of 45 water pixels, it only classifies 30 pixels correctly.

It is due to the mixed pixel problem. As water pixels are mixed with built-up and planted/cultivated pixels. Similarly, built-up pixels are mixed with open/bare land and out of 78 pixels 76 pixels are classified correctly through MLC method. Of this overall accuracy, the water cover class yielded the lowest producer's accuracy

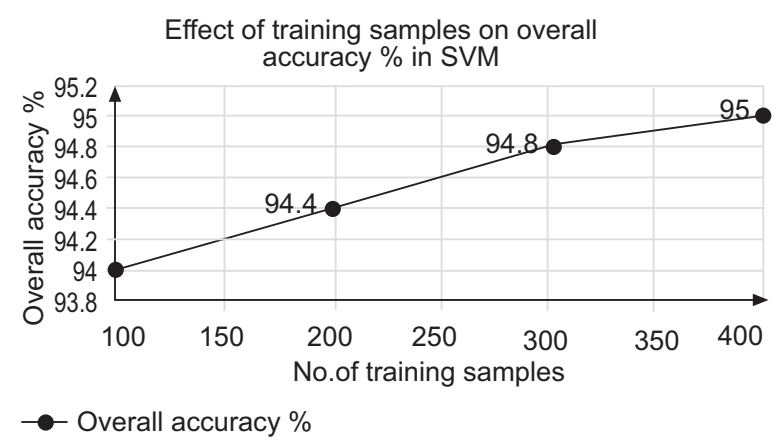

Fig. 8. Effect of training samples on overall accuracy in SVM.

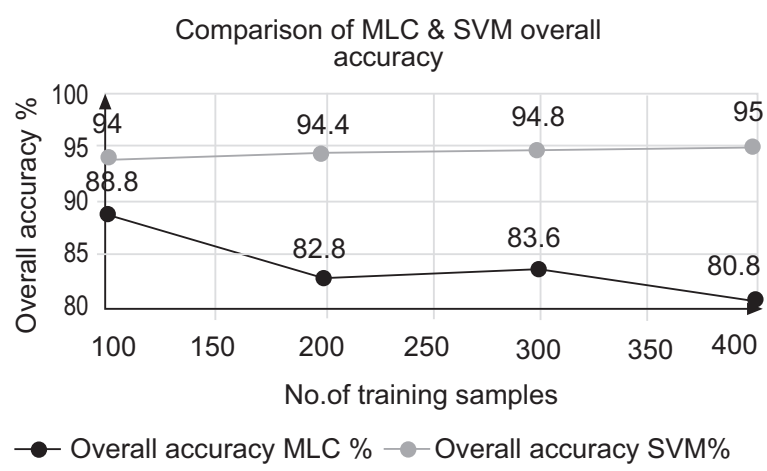

Fig. 9. Overall accuracy comparison between MLC and SVM.

of only $66.67 \%$. The other three classes were fair, with the producer's accuracy of $97.44 \%$ for the built-up area class, $93.33 \%$ for the planted/cultivated class and 88.46 $\%$ for the open/bare class Table 4.

The SVM method produced a higher accuracy, with an overall accuracy of $95.20 \%$. This method also provided higher user's accuracy for each land cover class. It behaves differently in respect to separate every class and provides significant separating hyper-plane for each class than the decision boundaries in MLC. Built-up land had the greatest increase from $80.00 \%$ using MLC method to $90.24 \%$ with the SVM method. Open/bare class had increase of $5 \%$ in accuracy using SVM approach. Planted/cultivated class increased only moderately with a $2 \%$ increase while water accuracy remains the same (Table 4). Although both the classifiers have resulted into good accuracy and reliability but SVM is found relatively better than MLC. A similar result for this comparison has been reported by Szuster et al. (2011) for Thailand. He has used ASTER data with spatial resolution of $15 \mathrm{~m}$ and have successfully obtained accuracy of $94.15 \%$ and $93.9 \%$ for SVM and MLC respectively. The use of better spatial and spectral resolutions in the current study has improved this accuracy to $95.20 \%$ for SVM. This comparison is clearly indicating supremacy of higher spatial resolution. Another difference found by current study is the accuracy gap between both the classifiers which is higher than shown by Szuster et al. (2011) and is surely controlled by spatial resolution of the used data.

Kappa statistics. Highest Kappa coefficients of both the classification techniques were compared. It is interesting to note that kappa coefficient of water class in both classification is 1 because the number of total classified pixels and the number of total correct classified 
Table 4. Land cover classification accuracy (\%) of two classifiers.

\begin{tabular}{|c|c|c|c|c|c|}
\hline \multicolumn{6}{|c|}{ SVM } \\
\hline Classes name & Built up & Open/ Bare land & Planted/ Cultivated land & Water & Total \\
\hline Classified totals & 82 & 49 & 74 & 45 & 250 \\
\hline Reference totals & 78 & 52 & 75 & 45 & 250 \\
\hline No of correct points & 74 & 48 & 71 & 45 & 238 \\
\hline Producers accuracy (\%) & 94.87 & 92.31 & 94.67 & 100.00 & $\ldots$ \\
\hline Users accuracy $(\%)$ & 90.24 & 97.96 & 95.95 & 100.00 & $\ldots$ \\
\hline Overall accuracy & $95.20 \%$ & & & & \\
\hline \multicolumn{6}{|c|}{ MLC } \\
\hline Classes name & Built up & Open/ Bare land & Planted/ Cultivated land & Water & Total \\
\hline Classified totals & 95 & 50 & 75 & 30 & 250 \\
\hline Reference totals & 78 & 52 & 75 & 45 & 250 \\
\hline Number of correct points & 76 & 46 & 70 & 30 & 222 \\
\hline Producers accuracy (\%) & 97.44 & 88.46 & 93.33 & 66.67 & $\ldots$ \\
\hline Users accuracy $(\%)$ & 80.00 & 92.00 & 93.33 & 100.00 & $\ldots$ \\
\hline Overall accuracy & $88.80 \%$ & & & & \\
\hline
\end{tabular}

pixels are same in both methods (45 in SVM and 30 in MLC) but the number of misclassified pixels are large in MLC than SVM. Other three classes also show remarkable accuracy in SVM method. Kappa accuracy increases 0.15 in built-up land cover from 0.70 in MLC to 0.85 in SVM, 0.04 in planted/cultivated land cover from 0.90 in MLC to 0.94 in SVM and 0.08 in open/bare land cover from 0.89 in MLC to 0.97 in SVM. Therefore, SVM shows overall kappa accuracy of 0.93 and MLC shows 0.84 (Table 5).

Srivastava et al. (2012) recorded Kappa accuracy of SVM as 0.74 higher than MLC which is 0.71 . The difference is less because number of bands used in this study was four (Landsat TM), while bands used in this research are ten (Sentinel-2). Besides this the total numbers of correct classification pixels were 236 out of 250 in SVM and 202 out of 250 in MLC. Range of kappa coefficient is from -1 to 1 . 0 indicates that classification is no better than a random classification. -1 indicates that classification is worse than the random classification while values close and equal to 1 indicate that classification is remarkably better than the random classification.

Areal statistics of MLC and SVM. Area from builtup land cover from MLC and SVM methods are 779.43 $\mathrm{km}^{2}$ and $670.96 \mathrm{~km}^{2}$ respectively. The complete areal statistics of each land cover class using SVM and MLC methods is shown in Table 6 .

With the help of MLC and SVM results, spatial similarity of each land cover class has been calculated. About $277.22 \mathrm{~km}^{2}$ area is computed as dissimilar spatial area
Table 5. Kappa statistics

\begin{tabular}{lccccc}
\hline \hline $\begin{array}{l}\text { Classes } \\
\text { name }\end{array}$ & $\begin{array}{c}\text { Built } \\
\text { up }\end{array}$ & $\begin{array}{l}\text { Open/ } \\
\text { bare } \\
\text { land }\end{array}$ & $\begin{array}{c}\text { Planted/ } \\
\text { cultivated } \\
\text { land }\end{array}$ & Water & $\begin{array}{l}\text { Overall } \\
\text { kappa } \\
\text { statistic }\end{array}$ \\
\hline MLC & 0.70 & 0.89 & 0.90 & 1.00 & 0.84 \\
SVM & 0.85 & 0.97 & 0.94 & 1.00 & 0.93 \\
\hline \hline
\end{tabular}

while, $1483.83 \mathrm{~km}^{2}$ area is computed as spatially similar. Thus, the unmatched and matched areas correspond to $15.74 \%$ and 84.17 respectively. Figure 10 shows the matched and unmatched spatial similarity of the both classification results.

Conclusion and recommendation. Mapping a heterogeneous land cover types is always a task for researchers. The findings of this study suggests that with the help of medium scale imagery (10-m Sentinel-2), support vector machine classifier can outstands its performance in comparing with the other classifier and can be used as a suitable land cover classification tool with an overall accuracy of $95.20 \%$ and kappa coefficient of 0.93 . Also, SVM performed better in higher dimensional data and classify the mixed classes over the Lahore district. Whereas the other compared technique of maximum likelihood classifier has resulted into an overall accuracy of $88.80 \%$ with kappa coefficient of 0.84 . The sample data taken to check accuracy of the classifiers is Sentinal$2 \mathrm{~A}$, so it may be concluded here that SVM performs better than MLC for spectral ranges and resolution of Sentinel-2A images and may varies if used with other datasets having different spectral ranges. As the accuracy of SVM is very good, it is recommended to use for hyper- 
Table 6. Areal statistics of MLC and SVM

\begin{tabular}{lllllll}
\hline \hline \multicolumn{2}{c}{ land classes } & Built up & $\begin{array}{l}\text { Open/ Bare } \\
\text { land }\end{array}$ & $\begin{array}{l}\text { Planted/ Cultivated } \\
\text { land }\end{array}$ & Water & Total \\
\hline MLC & Area $\left(\mathrm{km}^{2}\right)$ & 557.68 & 392.23 & 806.10 & 7.87 & 1762.74 \\
& Area $(\%)$ & 31.63 & 22.27 & 45.72 & 0.44 & 100 \\
SVM & Area $\left(\mathrm{km}^{2}\right)$ & 715.17 & 294.07 & 743.10 & 12.40 & 1762.74 \\
& Area $(\%)$ & 40.57 & 16.70 & 42.15 & 0.72 & 100 \\
\hline \hline
\end{tabular}

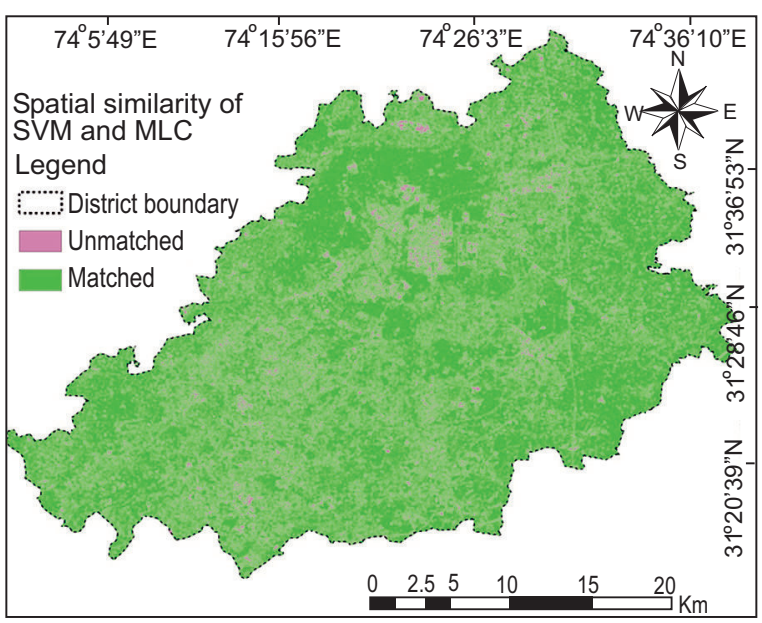

Fig. 10. Spatial similarity of SVM and MLC.

spectral imageries. Accuracy of SVM is based upon the kernel and parameter. So a sensitivity analysis of different kernels can be performed to extract the land cover information. More classes can be added to cultivated/agricultural land cover in order to extract detailed information about crop types in the specific area and built-up area can be further divided into dense, moderate, low density areas so that population density can be estimated precisely. High resolution satellites are recommended for classification purposes because they serve the diverse needs and various applications of urban and agricultural development, risk assessment and planning and policy making. In this regard, Pakistan has launched its first high resolution remote sensing satellite (PRSS) and its data availability will be very useful to classify different land cover of Pakistan accurately.

Conflict of Interest. The authors declare no conflict of interest.

\section{References}

Abdi, A.M. 2020. Land cover and land use classification performance of machine learning algorithms in a boreal landscape using Sentinel-2 data. GIScience \& Remote Sensing, 57: 1-20. (https://doi.org/10. 1080/15481603.2019.1650447)

Brar, G.S. 2013. Detection of land use and land cover change with Remote sensing and GIS: A case study of Punjab Siwaliks. International Journal of Geomatics and Geosciences, 4: 296-304. (https:// www.semanticscholar.org/paper/Detection-of-landuse-and-land-cover-change-with-A-Brar/ 1667abddcd5cb786cbb68543c26580f2d3555f20)

Census. 2017. Provisional summary results of $6^{\text {th }}$ population and housing census-2017. Pakistan bureau of statistics. (http://www.pbs.gov.pk/content/ provisional-summary-results- $6^{\text {th }}$-population-andhousing-census-2017-0)

Chiemelu, N.E., Onwumere, V.O. 2013. Land information systems for efficient land administration and revenue generation: a case study of tans-amadi industrial layout. Port Harcourt, Nigeria, Journal of Information Engineering and Application, 3: 13-23. (https://www.iiste.org/Journals/index.php/ JIEA/article/view/8920)

Chrysoulakis, N., Abrams, M., Feidas, H., Arai, K. 2010. Comparison of atmospheric correction methods using ASTER data for the area of Crete, Greece. International Journal of Remote Sensing, 31: 6347-6385. (https://www.researchgate.net/ publication/253497600)

Cui, H.S. 2019. Sub-urban land classification using GF2 images and support vector machine method. In: Proceedings of International Conference on Advances in Civil and Ecological Engineering Research, pp. 351 012028, Kaohsiung, Taiwan. (https://iopscience.iop.org/article/10.1088/17551315/351/1/012028/meta)

Gupta, M., Srivastava, P.K. 2010. Integrating GIS and remote sensing for identification of groundwater potential zones in the hilly terrain of Pavagarh, Gujarat, India. Water International, 35: 233-245. (https://www.tandfonline.com/doi/full/10.1080/0 
2508061003664419)

Hütt, C., Koppe, W., Miao, Y., Bareth, G. 2016. Best accuracy land use/land cover (LULC) classification to derive crop types using multi-temporal, multisensor, and multi-polarization SAR satellite images. Remote Sensing, 8: 684. (https://doi.org/10.3390/ rs8080684)

Ngo, K.D., Lechner, A.M., Vu, T.T. 2020. Land cover mapping of the Mekong delta to support natural resource management with multi-temporal Sentinel1A synthetic aperture radar imagery. Remote Sensing Applications: Society and Environment, 17: 100272. (https://doi.org/10.1016/j.rsase.2019. 100272)

Nitze, I., Schulthess, U., Asche, H. 2012. Comparison of machine learning algorithms random forest, artificial neural network and support vector machine to maximum likelihood for supervised crop type classification. In: Proceedings of $4^{\text {th }}$ GEOBIA, pp. 35, Rio de Janeiro - Brazil. (https://www.research gate.net/profile/Ingmar_Nitze/publication/27564 1579)

Olmanson, L.G., Bauer, M.E. 2017. Land cover classification of the lake of the woods/rainy river Basin by object-based image analysis of Landsat and lidar data. Lake and Reservoir Management, 33: 335-346. (https://doi.org/10.1080/10402381. 2017.1373171)

Otukei, J.R., Blaschke, T. 2010. Land cover change assessment using decision trees, support vector machines and maximum likelihood classification algorithms. International Journal of Applied Earth Observation and Geoinformation, 12: S27-S31. (https://doi.org/10.1016/j.jag.2009.11.002)

Puletti, N., Chianucci, F., Castaldi, C. 2018. Use of Sentinel-2 for forest classification in Mediterranean environments. Annals of Silvicultural Research, 42: 32-38. (http://dx.doi.org/10.12899/asr-1463)

Riaz, O., Ghaffar, A., Butt, I. 2014. Modelling land use patterns of Lahore (Pakistan) using remote sensing and GIS. Global Journal of Science Frontier Research. Environment \& Earth Science, 14: 2430. (https://www.researchgate.net/profile/Omar_ Riaz/publication/281741257)

Sajjad, S.H., Batool, R., Qadri, S.T., Shirazi, S.A., Shakrullah, K. 2015. The long-term variability in minimum and maximum temperature trends and heat island of Lahore city, Pakistan. Science
International, 27: 1321-1325. (https://www.research gate.net/profile/Sm_Talha_Qadri/publication/280 802787)

Srivastava, P.K., Kiran, G., Gupta, M., Sharma, N., Prasad, K. 2012. A study on distribution of heavy metal contamination in the vegetables using GIS and analytical technique. International Journal of Ecology \& Development, 21: 89-99. (http://www. ceserp.com/cp-jour/index.php/ijed/article/ view/3936)

Szuster, B.W., Chen, Q. Borger, M.A. 2011.comparison of classification techniques to support land cover and land use analysis in tropical coastal zones. Applied Geography, 31: 525-532. (https://doi.org/ 10.1016/j.apgeog.2010.11.007)

Taati, A., Sarmadian, F., Mousavi, A., Pour, C.T.H., Shahir, A.H.E. 2015. Land use classification using support vector machine and maximum likelihood algorithms by Landsat 5 TM images. Walailak Journal of Science and Technology, 12: 681-687. (https://doi.nrct.go.th//ListDoi/listDetail? Resolve_DOI=10.14456/wjst.2015.33)

Thanh N.P., Kappas, M. 2018. Comparison of random forest, k-nearest neighbor, and support vector machine classifiers for land cover classification using Sentinel-2 imagery. Sensors, 18:18. (https:// doi.org/10.3390/s18010018)

Ustuner, M., Sanli, F.B., Dixon, B. 2015. Application of support vector machines for landuse classification using high-resolution RapidEye images: a sensitivity analysis. European Journal of Remote Sensing, 48: 403-422. (https://doi.org/10.5721/EuJRS20154823)

Vanonckelen, S., Lhermitte, S., Rompaey, A.V. 2013. The effect of atmospheric and topographic correction methods on land cover classification accuracy. International Journal of Applied Earth Observation and Geoinformation, 24: 9-21. (https:// doi.org/10.1016/j.jag.2013.02.003)

Varma, M.K.S., Rao, N.K.K., Raju, K.K., Varma, G.P.S. 2016. Pixel-based classification using support vector machine classifier. In: Proceedings of IEEE $6^{\text {th }}$ International Conference on Advanced Computing, pp. 51-55, Bhimavaram, India (https://ieeexplore. ieee.org/abstract/document/7544809)

Wulder, M.A., Coops, N.C., Roy, D.P., White, J.C., Hermosilla, T. 2018. Land cover 2.0. International Journal of Remote Sensing, 39: 4254-4284. (https:// doi.org/10.1080/01431161.2018.1452075) 